http://jmscr.igmpublication.org/home/

ISSN (e)-2347-176x ISSN (p) 2455-0450

crossref DOI: https://dx.doi.org/10.18535/jmscr/v7i12.139

\title{
Analysis of Relationship between Carcinoma Breast and Expression of Ki67 - A Prospective Study
}

\author{
Authors \\ Madhushankar L, Shashank K A*, Gurunath Reddy \\ Department of General Surgery, Kempegowda Institute of Medical Sciences and Research Centre, \\ Bengaluru, Karnataka, India \\ *Corresponding Author \\ Dr Shashank K A
}

\begin{abstract}
Background: Breast cancer is the most common of all cancers and is the leading cause of cancer deaths in women worldwide, accounting for $>1.6 \%$ of deaths and case fatality rates are highest in low-resource countries. Prognostic factors include the type of tumor, size of the tumor, tumor grade, number of involved lymph nodes, Ki67 status (cellular marker for proliferation), and the patient's age. Numerous studies have been conducted on these prognostic factors and their relationships with one another, however, the studies have not reported proper association of Ki67 proliferative index with other clinicopathological parameters. Breast cancer aggressiveness can be correlated with proliferation status of tumor cells, which can be obtained with Ki67 marker. the present study is considered to analyze the association of Ki67 with tumor size, lymph node involvement, histological grade, ER, PR, HER2 status in breast carcinoma.These predictive and prognostic factors help us to stage, plan and choose an appropriate mode of management that increases the patients longevity and improves their quality of life.

Methods: In this prospective observational study, all the excised mastectomy specimens of patients with carcinoma breast were processed. Histological Grading of tumor was done based on modified Bloom and Richardson score and lymphovascular invasion, surgical margin status and metastatic lymph node deposits were noted. Paraffin blocks were selected for immunohistochemistry and four marker panel including ER, $P R, H E R 2$ and proliferative index Ki67 were done and studied along with controls.The parameters used were: age, tumor size, stage of the disease, number of lymph nodes positive, HPE grade, ER, PR, HER2, Ki67. Statistical analysis was done.

Results: Total 41 cases were taken for the study. Patients age ranged between 25 to 75 years, most were between 40-50 years of age. The mean age of presentation was $49.22 \pm 11.21$ years. $75.6 \%$ patients had Ki67 between 22-40\% indicating that younger the age group more aggressive is the breast cancer. Ki67 expression decreased as the patient's age increased. Tumors were between 1.6 to $10 \mathrm{~cm}$ in size in greatest dimension and most were between 3 to $6 \mathrm{~cm}$. As tumor size increased, an increased expression level of Ki-67 was noticed. A positive relationship was observed between involved lymph nodes and the mean level of Ki67 expression. On histopathological examination tumour grade-III had high Ki67 and proliferative index was gradually increasing from grade-I to grade-III. Proliferative index Ki67 was also compared with stage of disease in non metastatic breast cancer, it was found to be higher in later stage of disease. This study demonstrated HER2/-neu positivity with higher frequency of Ki67. A significant relationship was also found between Ki67 and tumor grade and age of the patient.A positive relationship was observed between
\end{abstract}


the mean level of Ki67 expression and involved lymph nodes. Ki67 expression thus affects the prognosis of breast cancer along with other factors, including the size and grade of tumor.

Conclusion: Ki-67 expression along with IHC markers for ER, PR and HER2neu is known to be correlating with histopathological grades, but was shown to be an independent prognostic and predictive factor in carcinoma of breast. High index labelled Ki67 is considered as an unfavourable factor that influences tumour progression and is associated with poorer prognosis. It helps in counselling the patient about prognosis of the disease. In conclusion, Ki-67 has great potential as prognostic biomarker in aggressive breast cancers and such prognostic information could be beneficial for development of therapeutic strategy. It would be easy to include it in the panel of markers routinely assessed in clinical practice.

Keywords: Carcinoma breast, Ki67, Prognostic biomarker, Histopathology, IHC.

\section{Introduction}

Breast cancer is the most common of all cancers and is the leading cause of cancer deaths in women worldwide ${ }^{1}$, accounting for $>1.6 \%$ of deaths and case fatality rates are highest in low-resource countries. A recent study of breast cancer risk in India revealed that 1 in 28 women develop breast cancer during her lifetime. This is higher in urban areas being 1 in 22 in a lifetime compared to rural areas where this risk is relatively much lower being 1 in 60 women developing breast cancer in their lifetime. The average age of the high risk group in India is 43-46 years unlike in the west where women aged 53-57 years are more prone to breast cancer. (Tata Memorial Hospital, 2013)

It is the most common female cancer reported in Trivandrum and Mumbai, and the second most frequent in Bangalore, Delhi and Chennai (Cancer Incidence: Biennal Report, 2004-2005). The two leading sites breast and cervix constituted $42 \%$ of the total cancers. The respective CR and AAR per $1,00,000$ population for the above sites were: breast (24.0 and 30.9).

The mortality rate has been significantly reduced in recent years because of its early diagnosis and the advanced methods of treatment. The behaviour of breast carcinoma can be assessed by various predictive and prognostic factors. Predictive factors determine the response to treatment. Prognostic factors are associated with the nature of the disease.

Some of them represent both predictive and prognostic factors, such as estrogen receptor (ER) and progesterone receptor (PR) status, p53 mutation status, and human epidermal growth factor receptor (HER2/neu) over expression. Prognostic factors include the type of tumor, size of the tumor, tumor grade, number of involved lymph nodes, Ki67 status (cellular marker for proliferation), and the patient's age ${ }^{9}$. Numerous studies have been conducted on these prognostic factors and their relationships with one another, however, the studies have not reported proper association of $\mathrm{Ki} 67$ proliferative index with other clinicopathological parameters. Breast cancer aggressiveness can be correlated with proliferation status of tumor cells, which can be obtained with Ki67 marker. Ki67 is a nuclear non-histone protein and an antigen associated with cell proliferation, expressed in G1, S, G2, and mitosis, but not in G0.

Therefore, the present study is considered to analyze the association of Ki67 with tumor size, lymph node involvement, histological grade, ER, PR, HER2 status in breast carcinoma.These predictive and prognostic factors help us to stage, plan and choose an appropriate mode of management that increases the patients longevity and improves their quality of life.

\section{Methods}

This prospective observational study was conducted at Department of Surgery, Kempegowda Institute of Medical Sciences, Bengaluru from December 2016 to July 2018 with sample size of 41 cases. All the excised mastectomy specimens were processed in the Department of Pathology at Kempegowda Institute of Medical Sciences, Bengaluru. All patients 
admitted with clinically and FNAC proved carcinoma of breast were included in this study. Recurrent breast carcinoma, inflammatory breast carcinoma, occult axillary lymph node with no palpable primary breast carcinoma, breast carcinoma during pregnancy, neoadjuvant chemotherapy given outside, metastasis to breast, male breast carcinoma, soft tissue tumors of breast other than carcinoma of breast like sarcomas, phyllodes tumor etc., breast papilloma, excision biopsy done outside, squamous cell (epidermoid) carcinoma were excluded from the study. Ethical committee clearance was taken prior to the study. Patients were admitted in general surgery inpatient department after diagnosis by history and clinical examination. All routine investigations were done and relevant clinical details were noted. Routine blood investigations were done with FNAC of breast lesion or trucut biopsy, Xray spine with thoracolumbar region, Ultrasound scan of abdomen and pelvis, bone scan.

FNAC / Biopsy proved patients with breast cancer were subjected for modified radical mastectomy (auchincloss). Suspected or inconclusive patients were posted for excision biopsy and frozen section, and if positive for malignancy, underwent modified radical mastectomy.

Biopsy specimens along with clinical details were sent to the department of pathology for histopathological examination. The specimens were grossed, description of the external and cut surfaces were noted along with consistency and the number of lymphnodes dissected. Bits were processed routinely and Haematoxylin and Eosin stained sections were studied.

Histological Grading of tumor was done based on modified Bloom and Richardson score and lymphovascular invasion, surgical margin status and metastatic lymph node deposits were noted. Paraffin blocks were selected for immunohistochemistry and four marker panel including ER, PR, HER2 and proliferative index Ki67 were done and studied along with controls.The results were statistically analyzed and compared with known previous studies. The parameters used were: age, tumor size, stage of the disease, number of lymph nodes positive, HPE grade, ER, PR, HER2, Ki67.

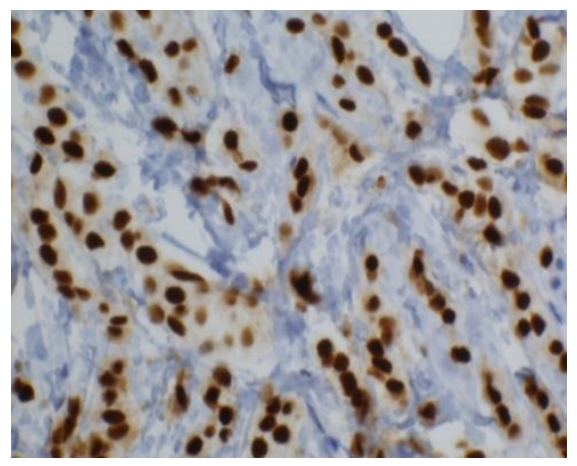

ER staining in breast carcinoma

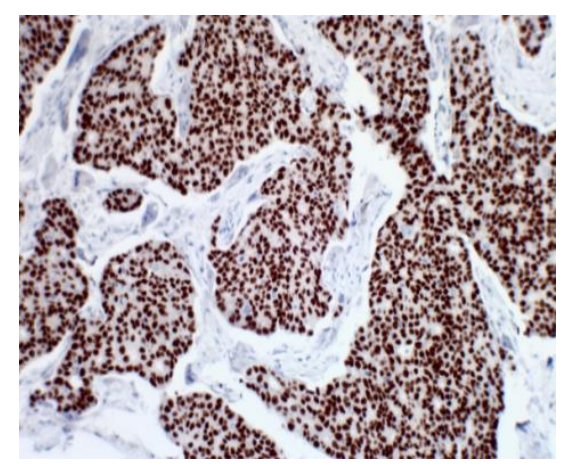

PR staining in breast carcinoma

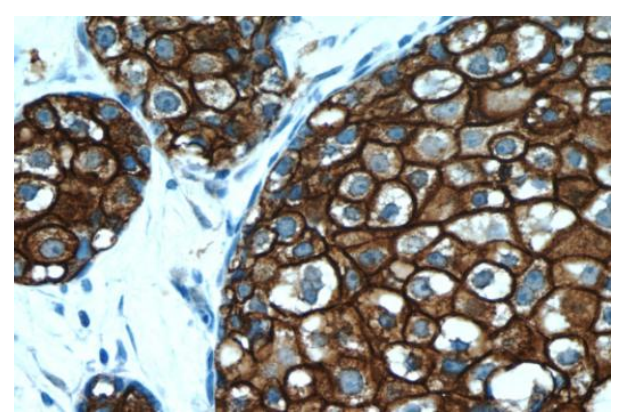

HER 2 nu staining in breast carcinoma

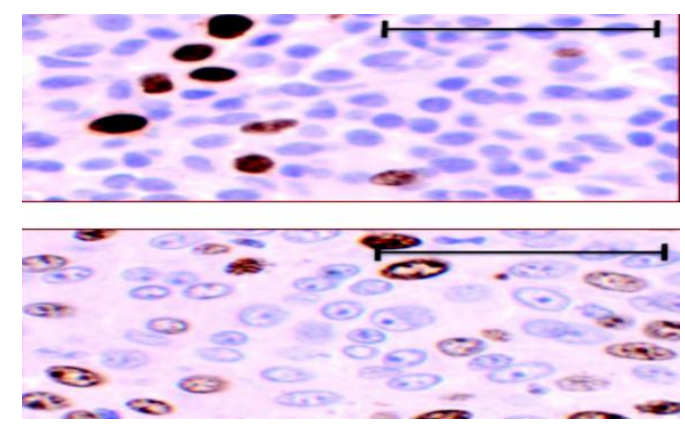

Ki67 staining in breast carcinoma

\section{Statistical Analysis}

The demographic details, data from clinical history such as side and duration of lump, 
complaints of pain, nipple retraction and clinically assessed tumor size in its greater dimensions; ultrasonographic tumor size and; data from histopathological examination following biopsy such as staging, number of positive axillary lymph nodes, grading, ER/PR/HEGF R positivity status and Ki-67 levels were entered as a spreadsheet in Microsoft ${ }^{\circledR} \quad$ Excel and coded appropriately. Double entry was utilized as a technique to reduce errors during the transformation of data from paper to electronic format. After cross - checking for any duplication and omissions, the data was subjected to statistical analysis using IBM ${ }^{\circledR}$ SPSS ver. 18.0.

Descriptive statistics were presented as mean $( \pm$ standard deviation), proportion and percentage. The association of age and Ki-67 with stage was determined by "Fisher Exact test" and; Ki-67 with ER, PR, HEGF $R$ status and grading by histopathological examination was determined by "Student t test". Pearson's correlation was determined for Ki-67 with tumor size in cms, USG tumor size in cms and number of axillary lymph nodes positive for tumor cells. Results were presented as tables, graphs and figures as appropriate.

Analysis of variance (ANOVA) has been used to find the significance of study parameters between three or more groups of patients, student $t$ test (two tailed, independent) has been used to find the significance of study parameters on continuous scale between two groups (Inter group analysis) on metric parameters. Chi-square/ Fisher Exact test has been used to find the significance of study parameters on categorical scale between two or more groups, Non-parametric setting for qualitative data analysis. Fisher Exact test was used when cell samples were very small.

Statistical software: The Statistical software namely SPSS 18.0, and R environment ver.3.2.2 were used for the analysis of the data and Microsoft word and Excel have been used to generate graphs, tables etc.

\section{Results}

Total 41 patients were taken for the study after admitting with diagnosis of breast carcinoma.

\section{Baseline Characteristics of Study Population}

\section{Age}

Table 1: Age distribution of patients studied

\begin{tabular}{|l|c|c|}
\hline Age in years & No. of patients & \% \\
\hline$<\mathbf{4 0}$ & 9 & 22.0 \\
\hline $\mathbf{4 1 - 5 0}$ & 13 & 31.7 \\
\hline $\mathbf{5 1 - 6 0}$ & 12 & 29.3 \\
\hline$>\mathbf{6 0}$ & 7 & 17.1 \\
\hline Total & $\mathbf{4 1}$ & $\mathbf{1 0 0 . 0}$ \\
\hline
\end{tabular}

\section{Side of Lump}

Among the study subjects, greater proportion (54\%) presented with a left-sided lump

\section{Duration of Lump}

While $61 \%$ patients presented with breast lump early to hospital within 4 months, $14.6 \%$

presented after a prolonged duration of 8 months. About a quarter (24.4\%) presented between 4-8 months

\section{Pain Distribution}

Only $12 \%$ of the patients complained of pain in the lump at the time of presentation

\section{Nipple Retraction}

Only $17 \%$ of the patients had nipple retraction on the time of presentation

\section{Tumour Size Clinically}

\section{Tumor Size By USG}

The highest number of patients were in the category of 3-6 cm when assessed clinically and the same was true for ultrasonographic findings. Clinically, a larger number of patients (36.5\%) had $<3 \mathrm{~cm}$ size of tumor, whereas ultrasonography confirmed the size only in $17.1 \%$ of the subjects. The proportion of subjects having $>8 \mathrm{~cm}$ large tumor was small, clinically $14.6 \%$ whereas ultrasonographically $17.1 \%$. The USG measurements were considered in this study. 


\section{Stage}

The most frequent stage of presentation was IIa (31.7\%), followed by IIb and IIIb at $26.8 \%$ each, while stages IIIa (9.8\%) and IIIc (4.9\%)were under $10 \%$.

\section{Number of Axillary Lymph Nodes Positive for Tumor Cells}

$60 \%$ cases were positive for $<4$ axillary group of lymph nodes on histopathological examination.

\section{Diagnosis on Histopathology Examination}

93\% cases had invasive ductal carcinoma, two cases with invasive lobular carcinoma and one case with intra cystic papillary carcinoma on histopathological examination.

\section{Histopathology Grading of Tumor}

97\% patients found to have tumor with grade-II and grade-III bu only one patient had grade-I tumor.

\section{ER/PR/HER-2}

Table 2: ER/PR/HER-2 Distribution

\begin{tabular}{|l|c|c|}
\hline & $\begin{array}{c}\text { No. of patients } \\
(\mathbf{n = 4 1})\end{array}$ & $\%$ \\
\hline Estrogen receptor & 24 & 58.5 \\
\hline Progesterone receptor & 21 & 51.2 \\
\hline $\begin{array}{l}\text { Human epidermal growth } \\
\text { factor receptor }\end{array}$ & 16 & 39.0 \\
\hline
\end{tabular}

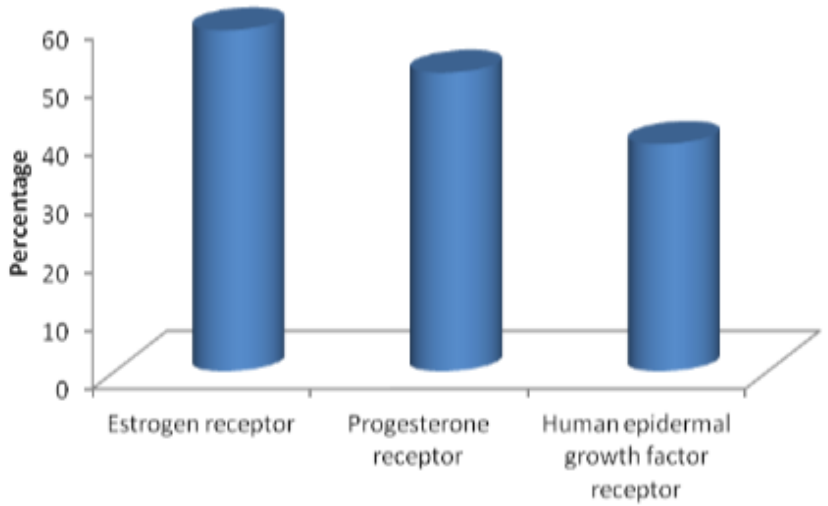

While the positive status for ER was among 58.5\% and for PR was among $51.2 \%$ of the subjects, Her-2/Neu was seen to be positive only among $39 \%$ of the subjects

\section{Ki67 Distribution of Patients Studied}

Table 3: Ki67 distribution

\begin{tabular}{|l|c|c|}
\hline Ki67 & No. of patients & \% \\
\hline$<\mathbf{2 0}$ & 4 & 9.8 \\
\hline $\mathbf{2 0 - 3 0}$ & 21 & 51.2 \\
\hline $\mathbf{3 0 - 4 0}$ & 10 & 24.4 \\
\hline $\mathbf{4 0 - 5 0}$ & 3 & 7.3 \\
\hline$>\mathbf{5 0}$ & 3 & 7.3 \\
\hline Total & $\mathbf{4 1}$ & $\mathbf{1 0 0 . 0}$ \\
\hline
\end{tabular}

The Ki-67 status was in the range of $20-30$ for $51.2 \%$ of patients whereas in the range of 30-40 for $24.4 \%$ of the patients. Other ranges had less than $10 \%$ patients in each.

\section{Analytical Statistics}

\section{Age Distribution of Patients in Relation to Stage}

Table 4: Age distribution in relation to stage

\begin{tabular}{|l|c|c|c|c|c|c|}
\hline \multirow{2}{*}{ Age in years } & \multicolumn{5}{|c|}{ Stage } & \multirow{2}{*}{ Total } \\
\cline { 2 - 6 } & IIa & IIb & IIIa & IIIb & IIIc & \\
\hline$<30$ & $0(0 \%)$ & $1(9.1 \%)$ & $0(0 \%)$ & $1(9.1 \%)$ & $0(0 \%)$ & $\mathbf{2}(\mathbf{4 . 9 \%})$ \\
\hline $\mathbf{3 0 - 4 0}$ & $2(15.4 \%)$ & $2(18.2 \%)$ & $1(25 \%)$ & $2(18.2 \%)$ & $0(0 \%)$ & $\mathbf{7 ( 1 7 . 1 \% )}$ \\
\hline $\mathbf{4 1 - 5 0}$ & $4(30.8 \%)$ & $3(27.3 \%)$ & $1(25 \%)$ & $4(36.4 \%)$ & $1(50 \%)$ & $\mathbf{1 3}(\mathbf{3 1 . 7} \%)$ \\
\hline $\mathbf{5 1 - 6 0}$ & $6(46.2 \%)$ & $1(9.1 \%)$ & $2(50 \%)$ & $3(27.3 \%)$ & $0(0 \%)$ & $\mathbf{1 2}(\mathbf{2 9 . 3 \%})$ \\
\hline $\mathbf{6 1 - 7 0}$ & $1(7.7 \%)$ & $4(36.4 \%)$ & $0(0 \%)$ & $1(9.1 \%)$ & $0(0 \%)$ & $\mathbf{6}(\mathbf{1 4 . 6 \%})$ \\
\hline$>70$ & $0(0 \%)$ & $0(0 \%)$ & $0(0 \%)$ & $0(0 \%)$ & $1(50 \%)$ & $\mathbf{1}(\mathbf{2 . 4 \%})$ \\
\hline Total & $\mathbf{1 3}(\mathbf{1 0 0 \%})$ & $\mathbf{1 1}(\mathbf{1 0 0 \%})$ & $\mathbf{4 ( 1 0 0 \% )}$ & $\mathbf{1 1}(\mathbf{1 0 0 \%})$ & $\mathbf{2 ( 1 0 0 \% )}$ & $\mathbf{4 1}(\mathbf{1 0 0 \%})$ \\
\hline $\mathrm{P}=0.541$
\end{tabular}


Ki67 Distribution in Relation to Stage

Table 5: Ki67 in relation to stage

\begin{tabular}{|l|c|c|c|c|c|c|}
\hline \multirow{2}{*}{ ki67 } & \multicolumn{5}{|c|}{ Stage } & \multirow{2}{*}{ Total } \\
\cline { 2 - 5 } & IIa & IIb & IIIa & IIIb & IIIc & \\
\hline$<\mathbf{2 0}$ & $2(15.4 \%)$ & $0(0 \%)$ & $0(0 \%)$ & $2(18.2 \%)$ & $0(0 \%)$ & $\mathbf{4 ( 9 . 8 \% )}$ \\
\hline $\mathbf{2 0 - 5 0}$ & $11(84.6 \%)$ & $10(90.9 \%)$ & $4(100 \%)$ & $7(63.6 \%)$ & $2(100 \%)$ & $\mathbf{3 4 ( 8 2 . 9 \% )}$ \\
\hline$>\mathbf{5 0}$ & $0(0 \%)$ & $1(9.1 \%)$ & $0(0 \%)$ & $2(18.2 \%)$ & $0(0 \%)$ & $\mathbf{3 ( 7 . 3 \% )}$ \\
\hline Total & $\mathbf{1 3}(\mathbf{1 0 0 \%})$ & $\mathbf{1 1}(\mathbf{1 0 0 \%})$ & $\mathbf{4 ( 1 0 0 \% )}$ & $\mathbf{1 1}(\mathbf{1 0 0 \%})$ & $\mathbf{2 ( 1 0 0 \% )}$ & $\mathbf{4 1 ( 1 0 0 \% )}$ \\
\hline $\mathrm{P}=0.604$
\end{tabular}

Ki67 in Relation to ER Positivity

Table 6: Ki67 in relation to ER positivity

\begin{tabular}{|l|c|c|c|}
\hline \multirow{2}{*}{ ki67 } & \multicolumn{2}{|c|}{ Estrogen receptor } & \multirow{2}{*}{ Total } \\
\cline { 2 - 3 } & Negative & Positive & \\
\hline$<\mathbf{2 0}$ & $0(0 \%)$ & $4(16.7 \%)$ & $\mathbf{4 ( 9 . 8 \% )}$ \\
\hline $\mathbf{2 0 - 3 0}$ & $7(41.2 \%)$ & $14(58.3 \%)$ & $\mathbf{2 1 ( 5 1 . 2 \% )}$ \\
\hline $\mathbf{3 0 - 4 0}$ & $5(29.4 \%)$ & $5(20.8 \%)$ & $\mathbf{1 0}(\mathbf{2 4 . 4 \% )}$ \\
\hline $\mathbf{4 0 - 5 0}$ & $3(17.6 \%)$ & $0(0 \%)$ & $\mathbf{3 ( 7 . 3 \% )}$ \\
\hline$>\mathbf{5 0}$ & $2(11.8 \%)$ & $1(4.2 \%)$ & $\mathbf{3 ( 7 . 3 \% )}$ \\
\hline Total & $\mathbf{1 7}(\mathbf{1 0 0 \%})$ & $\mathbf{2 4}(\mathbf{1 0 0 \% )}$ & $\mathbf{4 1 ( 1 0 0 \% )}$ \\
\hline Mean \pm SD & $\mathbf{3 8 . 6 5} \pm \mathbf{1 6 . 6 2}$ & $\mathbf{2 8 . 0 4} \pm \mathbf{1 2 . 9 2}$ & $\mathbf{3 2 . 4 4} \pm \mathbf{1 5 . 3 1}$ \\
\hline $\mathrm{P}=0.027$ & & &
\end{tabular}

Ki67 in Relation to PR Positivity

Table 7: Ki67 in relation to PR positivity

\begin{tabular}{|l|c|c|c|}
\hline \multirow{2}{*}{ ki67 } & \multicolumn{2}{|c|}{ Progesterone receptor } & \multirow{2}{*}{ Total } \\
\cline { 2 - 3 } & Negative & Positive & \\
\hline$<\mathbf{2 0}$ & $0(0 \%)$ & $4(19 \%)$ & $\mathbf{4 ( 9 . 8 \% )}$ \\
\hline $\mathbf{2 0 - 3 0}$ & $10(50 \%)$ & $11(52.4 \%)$ & $\mathbf{2 1 ( 5 1 . 2 \% )}$ \\
\hline $\mathbf{3 0 - 4 0}$ & $5(25 \%)$ & $5(23.8 \%)$ & $\mathbf{1 0}(\mathbf{2 4 . 4 \%})$ \\
\hline $\mathbf{4 0 - 5 0}$ & $3(15 \%)$ & $0(0 \%)$ & $\mathbf{3 ( 7 . 3 \% )}$ \\
\hline$>\mathbf{5 0}$ & $2(10 \%)$ & $1(4.8 \%)$ & $\mathbf{3 ( 7 . 3 \% )}$ \\
\hline Total & $\mathbf{2 0}(\mathbf{1 0 0 \%})$ & $\mathbf{2 1 ( 1 0 0 \% )}$ & $\mathbf{4 1}(\mathbf{1 0 0 \%})$ \\
\hline Mean \pm SD & $\mathbf{3 6 . 6 0} \pm \mathbf{1 6 . 1 3}$ & $\mathbf{2 8 . 4 8} \pm \mathbf{1 3 . 7 0}$ & $\mathbf{3 2 . 4 4} \pm \mathbf{1 5 . 3 1}$ \\
\hline $\mathrm{P}=0.090$ & &
\end{tabular}

The positivity of PR status did not show any significant association with the Ki-67 levels but the $\mathrm{p}$ value of 0.090 does suggest a possible significance if a larger sample size could be considered for the study.

\section{Ki67 Relation to HER-2 Positivity}

Table 8: Ki67 relation to HER2 positivity

\begin{tabular}{|l|c|c|c|}
\hline \multirow{2}{*}{ ki67 } & \multicolumn{2}{|c|}{ Human epidermal growth factor receptor } & \multirow{2}{*}{ Total } \\
\cline { 2 - 3 } & Negative & Positive & \\
\hline$<\mathbf{2 0}$ & $3(12 \%)$ & $1(6.3 \%)$ & $\mathbf{4}(\mathbf{9 . 8 \%})$ \\
\hline $\mathbf{2 0 - 3 0}$ & $14(56 \%)$ & $7(43.8 \%)$ & $\mathbf{2 1}(\mathbf{5 1 . 2 \%})$ \\
\hline $\mathbf{3 0 - 4 0}$ & $5(20 \%)$ & $5(31.3 \%)$ & $\mathbf{1 0}(\mathbf{2 4 . 4 \%})$ \\
\hline $\mathbf{4 0 - 5 0}$ & $0(0 \%)$ & $3(18.8 \%)$ & $\mathbf{3}(\mathbf{7 . 3 \%})$ \\
\hline$>\mathbf{5 0}$ & $3(12 \%)$ & $0(0 \%)$ & $\mathbf{3}(\mathbf{7 . 3 \%})$ \\
\hline Total & $\mathbf{2 5}(\mathbf{1 0 0 \%})$ & $\mathbf{1 6}(\mathbf{1 0 0 \%})$ & $\mathbf{4 1}(\mathbf{1 0 0 \%})$ \\
\hline Mean \pm SD & $\mathbf{3 1 . 6 0} \pm \mathbf{1 7 . 5 0}$ & $\mathbf{3 3 . 7 5} \pm \mathbf{1 1 . 4 7}$ & $\mathbf{3 2 . 4 4} \pm \mathbf{1 5 . 3 1}$ \\
\hline
\end{tabular}

$\mathrm{P}=0.667$, Not significant, student $\mathrm{t}$ test

The mean Ki-67 levels among those with HEGF R negative status was $31.60 \pm 17.50$, showing no positive was $33.75( \pm 11.47)$ while in those with significant difference among the 2 groups 
Ki67 Relation to Histopathological Examination

Table 9: Ki67 in relation to Histopathology

\begin{tabular}{|l|c|c|c|c|}
\hline \multirow{2}{*}{ ki67 } & \multicolumn{2}{|c|}{ Histopathological examination grading } & \multirow{2}{*}{ Total } \\
\cline { 2 - 4 } & Gr 1 & Gr 2 & Gr 3 & (9.8\%) \\
\hline$<\mathbf{2 0}$ & $0(0 \%)$ & $3(15.8 \%)$ & $1(4.8 \%)$ & $\mathbf{4} \%)$ \\
\hline $\mathbf{2 0 - 3 0}$ & $1(100 \%)$ & $11(57.9 \%)$ & $9(42.9 \%)$ & $\mathbf{2 1 ( 5 1 . 2 \% )}$ \\
\hline $\mathbf{3 0 - 4 0}$ & $0(0 \%)$ & $4(21.1 \%)$ & $6(28.6 \%)$ & $\mathbf{1 0}(\mathbf{2 4 . 4 \%})$ \\
\hline $\mathbf{4 0 - 5 0}$ & $0(0 \%)$ & $1(5.3 \%)$ & $2(9.5 \%)$ & $\mathbf{3}(\mathbf{7 . 3 \%})$ \\
\hline$>\mathbf{5 0}$ & $0(0 \%)$ & $0(0 \%)$ & $3(14.3 \%)$ & $\mathbf{3 ( 7 . 3 \% )}$ \\
\hline Total & $\mathbf{1 ( 1 0 0 \% )}$ & $\mathbf{1 9}(\mathbf{1 0 0 \%})$ & $\mathbf{2 1}(\mathbf{1 0 0 \% )}$ & $\mathbf{4 1}(\mathbf{1 0 0 \%})$ \\
\hline Mean \pm SD & $\mathbf{2 0 . 0 0} \pm \mathbf{0 . 0 0}$ & $\mathbf{2 7 . 3 7} \pm \mathbf{1 0 . 5 9}$ & $\mathbf{3 7 . 6 2} \pm \mathbf{1 7 . 5 3}$ & $\mathbf{3 2 . 4 4} \pm \mathbf{1 5 . 3 1}$ \\
\hline
\end{tabular}

The mean Ki-67 levels among patients with histopathologic grade 1 of tumor was 20 , grade 2 was $27.37( \pm 10.59)$ and grade 3 was 37.62 $( \pm 17.53)$.

\section{Pearson Correlation}

Table 10: Pearson Correlation

\begin{tabular}{|l|c|c|}
\hline Pearson correlation & r value & P value \\
\hline Ki67 vs Tumor size in cms clinically in its greatest dimension & $\mathbf{0 . 3 5 3}$ & $\mathbf{0 . 0 2 3} *$ \\
\hline Ki67 vs USG tumor size in cms & $\mathbf{0 . 3 6 6}$ & $\mathbf{0 . 0 1 9}$ \\
\hline Ki67 vs Number of axillary lymph nodes positive for tumor cells & $\mathbf{0 . 3 2 4}$ & $\mathbf{0 . 0 3 9} *$ \\
\hline
\end{tabular}

The Ki-67 shows a weak correlation with clinically measured tumor size $(\mathrm{r}=0.353)$, ultrasonographically measured tumor size $(\mathrm{r}=$ 0.366 ) and the number of axillary lymph nodes positive $(r=0.039)$. As evident from the $r^{2}$ values, only $12.5 \%$ of change in Ki-67 can be explained by change in clinically measured tumor size, $13.4 \%$ can be explained by change in USG tumor size and only $10.5 \%$ can be explained by number of positive axillary lymph nodes.

\section{Discussion}

This study was done to correlate Ki-67 marker and other prognostic parameters in patients with early and locally advanced breast cancer.

Total 41 cases were taken for the study. Patients age ranged between 25 to 75 years, most were between 40-50 years of age. The mean age of presentation was $49.22 \pm 11.21$ years. $75.6 \%$ patients had Ki67 between $22-40 \%$ indicating that younger the age group more aggressive is the breast cancer. Ki67 expression decreased as the patient's age increased, demonstrating that lower the Ki67 expression and the tumor is less invasive
The mean Ki-67 was clearly higher in higher grades and the difference across the 3 groups but was not found to be statistically significant. in older patients. This result was consistent with the results obtained by Vasseur et al, ${ }^{10}$ who found Ki67 expression to be higher in younger patients compared with older patients.

Tumour size measured both clinically and by ultrasonography, since accuracy was found more with USG, highest measurement on ultrasound was taken for study, tumors were between 1.6 to $10 \mathrm{cms}$ in size in its greatest dimension and most were between 3 to $6 \mathrm{cms}$. As tumor size increased, an increased expression level of Ki-67 was noticed.

In present study most of cases, it was <4 lymph nodes were positive for tumor deposits and it is noticed in $56.1 \%$ study group but the mean was found to be $4.22 \pm 5.10 \mathrm{cms}$ with $\mathrm{p}$ value of 0.466 which is statistically not significant. A positive relationship was observed between involved lymph nodes and the mean level of Ki67 expression ${ }^{11}$ these results are consistent with Yin, Y., Zeng, K., Wu, M. et al ${ }^{12}$. On histopathological examination tumour grade-III had high Ki67 and proliferative index was gradually increasing from grade-I to grade-III. 21 patients had grade-III 
tumor with higher proliferating index Ki67 with mean value of $37.62 \pm 17.53$, indicating low Ki67 associated with low grade, high Ki67 associated with high grade tumor which is statistically significant and $\mathrm{P}=0.073+$. Proliferative index Ki67 was also compared with stage of disease in non metastatic breast cancer, it was found to be higher in later stage of disease.

On analysis of receptor status, there is some association between Ki67 and ER (estrogen receptor), There were 24 ER positive primary tumors in the whole tumor set. Most ER positive cases expressed Ki67 frequency between 20-30\% $\mathrm{p}=0.027$, positivity for ER was found decreasing as Ki67 frequency increases. Positive estrogen receptor status in breast cancer is associated with a good response to hormonal therapy and to a good prognosis, a long disease-free and overall survival. $^{11}$

Progesterone Receptor(PR) has shown association with Ki67 in patients with breast carcinoma. 21 patients were positive for PR with mean Ki67 of 28.48 \pm 13.70 . Ki67 in most PR positive cases were between $20-30 \%$ which is statistically significant $\mathrm{P}=0.090+$. The additional prognostic and predictive value of the progesterone receptor has remained controversial ${ }^{11 .}$

Human Epidermal Growth factor receptor (HER2/-neu) was positive in only 16 cases with mean Ki67 - 33.75 $\pm 11.47 \%$, HER2/-neu positive patients express wide range Ki67 frequency between $20-40 \%$ and $\mathrm{P}=0.667$ this study demonstrated a HER2/-neu positivity with higher frequency of Ki67 like other studies ${ }^{12}$ but statistical $p$ value is high, if sample size was larger probably it could be a significant association. It could be demonstrated that high levels of Ki-67 are associated with HER2/-neu positivity according to former studies Viale et al. $^{12,13}$. In our study large number of tumors with HER2neu positivity were in grade-III according to Bloom Richardson grading.

A significant relationship was also found between Ki67 and tumor grade and age of the patient. As tumors with higher grades have higher levels of cell proliferation and are consequently more invasive than the other grades. A positive relationship was observed between the mean level of Ki67 expression and involved lymph nodes. Higher percentages of Ki67 expression result in more involved lymph nodes, making lymph node involvement a key issue to be considered in the case of Ki67-positive cells. Ki67 expression thus affects the prognosis of breast cancer along with other factors, including the size and grade of tumor.

\section{Conclusion}

This study was done to correlate Ki-67 marker and other prognostic parameters in patients with early and locally advanced breast cancer.

The present study was conducted in 41 patients of breast carcinoma to find an association of Proliferation index Ki-67 marker and other clinical and pathological parameters in patients with early and locally advanced breast cancer. In conclusion, the Ki-67 index had a wide distribution of $10-80 \%$ in our study in patients aged between 25 to 75 years. A higher Ki-67 index $(\geq 20 \%)$ correlated significantly with young age demonstrating more aggressive tumor and has poor prognosis.Size of the tumor is also important as large tumors expressed higher proliferative index.

A positive relationship was observed between the number of involved lymph nodes and the mean level of Ki67 expression, making lymph node involvement to be considered in the case of Ki67-positive tumors.Similarly, a significant association was demonstrated between proliferative index Ki67 and histological grade of the tumor specifically grade-II, grade-III and stage of the disease. Ki67 has shown some association with all breast tumor receptors including estrogen, progesterone and HER2/-neu. The current study demonstrated that Ki-67 can be widely applied in routine clinical work up of breast cancers. Over expression of Ki-67 in more than $20 \%-50 \%$ of the cells indicate high risk of developing recurrent disease. 
Ki-67 expression along with IHC markers for ER, PR and HER2neu is known to be correlating with histopathological grades, but was shown to be an independent prognostic and predictive factor in carcinoma of breast. High index labelled Ki67 is considered as an unfavourable factor that influences tumour progression and is associated with poorer prognosis. It helps in counselling the patient about prognosis of the disease. In conclusion, Ki-67 has great potential as prognostic biomarker in aggressive breast cancers and such prognostic information could be beneficial for development of therapeutic strategy. It would be easy to include it in the panel of markers routinely assessed in clinical practice.

Therefore, in this field, future work should focus on the standardization of $\mathrm{Ki}-67$ assessment in routine clinical settings and the role of $\mathrm{Ki}-67$ in treatment decisions.

\section{Bibliography}

1. Beauchamp, Evers, Matton. "Sabiston Textbook of Surgery 18th Ed The Biological Basis of Modern Surgical Practice".Vol.1,Chapter34:Pg851-898 Else vier

2. Wrensch M, Chew T et al. "Risk factors for breast cancer in a population with high incidence rates”. Breast Cancer Res, 2003. 5:R88-R102

3. Marchio et al. "Revisiting the technical validation of tumour biomarker assays: how to open a Pandora's Box". BMC Medicine, 2011. 9:41.

4. Teng et al. "Mutations in the epidermal growth factor receptor (EGFR) gene in triple negative breast cancer: possible implications for targeted therapy". Breast Cancer Research, 2011.13:R35.

5. Albergaria et al. "Nottingham Prognostic Index in Triple-Negative Breast Cancer: a reliable prognostic tool?" BMC Cancer, 2011. 11:299.

6. Porzand A, Fakre et a1. "Hormone Receptor Status in Breast Cancer and its relation to age and other Prognostic Factors". Liberates Academica. Breast Cancer: Basic \&amp; Clinical Research. $2011: 5$ 87-92

7. Nishimura R, Osako $\mathrm{T}$ et al. "Changes in ER, PgR, HER2, p53 and Ki67 biological markers between Primary and Recurrent Breast Cancer". World Journal of Surgical Oncology, 2011. 9:131.

8. Marchio C, Dowsett $\mathrm{M}$ et al. "Revisiting the technical validation of tumour biomarker assays: How to open Pandora's Box". BMC Medicine, 2011. 9:41

9. Bhagat $\mathrm{M}$, Jha $\mathrm{M}$ et al. "Correlation of Hormonal receptor and Her-2/neu Expression in Breast Cancer A study at Tertiary care Hospital in South Gujarat". National Journal of Medical Research, Sep 2012. Vol. 2. 3:295-298.

10. Vasseur F, Baranzelli MC, Fournier C, et al. Ki67 in young patients with breast cancer. Gynecol Obstet Fertil 2013; 41: 16-19.

11. Yin, Y., Zeng, K., Wu, M. et al. Cell Biochem Biophys (2014) 70: 1145.

12. Vollenweider-Zerargui L, Barrelet L, Wong Y, Lemarchand-Béraud T, Gómez F. The predictive value of estrogen and progesterone receptors' concentrations on the clinical behaviour of breast cancer in women. Clinical correlation on 547 patients. Cancer. 1986;57(6):1171-80.

13. Aleskandarany MA, Green AR, Benhasouna AA, Barros FF, Neal K, Reis-Filho JS, Ellis IO, Rakha EA. Prognostic value of proliferation assay in the luminal, HER2-positive, and triple-negative biologic classes of breast cancer. Breast Cancer Res. 2012;14(1):R3. doi: 10.1186/bcr3084.

14. Viale G, Giobbie-Hurder A, Regan MM, Coates AS, Mastropasqua MG, Dell'Orto P, Maiorano E, MacGrogan G, Braye SG, Ohlschlegel C, et al. Prognostic and predictive value of centrally reviewed 
Ki-67 labeling index in postmenopausal women with endocrine-responsive breast cancer: results from Breast International Group Trial 1-98 comparing adjuvant tamoxifen with letrozole. J Clin Oncol. 2008;26(34):5569-5575. doi: 10.1200/JCO.2008.17.0829.

15. Mitch Dowsett, Torsten O. Nielsen, Roger A'Hern, John Bartlett, R. Charles Coombes, Jack Cuzick, Matthew Ellis, N. Lynn Henry, Judith C. Hugh, Tracy Lively, Lisa McShane, Soon Paik, Frederique Penault-Llorca, Ljudmila Prudkin, Meredith Regan, Janine Salter, Christos Sotiriou, Ian E. Smith, Giuseppe Viale, Jo Anne Zujewski, Daniel F. Hayes; Assessment of Ki67 in Breast Cancer: Recommendations from the International Ki67 in Breast Cancer Working Group, JNCI: Journal of the National Cancer Institute, Volume 103, Issue 22, 16 November 2011, Pages 1656-1664

16. Cheang MC, Chia SK, Voduc D, et al. Ki-67 index, HER2 status, and prognosis of patients with luminal B breast cancer. J Natl Cancer Inst. 2009;101(10):736-50. 